\title{
Self-Assessment of Competencies by Bachelor Students in Computer Science
}

\author{
Autovalutazione delle competenze da parte degli studenti di laurea in \\ informatica
}

\author{
Kay Berklinga ${ }^{\mathrm{a}}$, Dirk Saller ${ }^{\mathrm{b}}$, Carmen Winter ${ }^{\mathrm{c}}$ \\ a Baden-Württemberg Cooperative State University Karlsruhe, kay.berkling@dhbw-karlsruhe.de \\ ${ }^{b}$ Baden-Württemberg Cooperative State University Mosbach, dirk.saller@mosbach.dhbw.de \\ ${ }^{c}$ Baden-Württemberg Cooperative State University Stuttgart, carmen.winter@dhbw-stuttgart.de
}

\begin{abstract}
Competency achievements in a Computer Science Bachelor are studied using selfassessment by graduating students at Baden-Württemberg Cooperative State University. Changes across the two 'pandemic' years 2020 and 2021 with respect to subsidiary, satisfaction and competencies are analysed. One goal was to identify which competencies may have suffered due to the different number of online semesters. The data shows very few significant differences by type of competencies. Larger differences may be due to a change in lecturer. Difference in satisfaction in some subsidiaries is found. Students from the 2021 group feel that their grades reflect their actual knowledge less than the 2020 group. The methodology presented here provides a valid tool for long-term quality assessment based on student feedback. There are limitations based on the data elicitation. Students are not required to take the survey. Self-assessment is not considered to be sufficient for a validation of achieved competencies. However, it reflects satisfaction and perceived quality.
\end{abstract}

Keywords: Online learning; COVID impact; competencies; computer science bachelor.

Sintesi

I risultati di apprendimento in un Corso di Laurea di primo livello di informatica sono analizzati utilizzando l'autovalutazione degli studenti laureati all'Università della Cooperative State University del Baden-Württemberg (Germania). Vengono analizzati i cambiamenti nella progressione di competenze acquisite nei due anni di pandemia (2020 e 2021 ) in ordine a sede universitaria, livello di soddisfazione e risultati di apprendimento. Un obiettivo è stato quello di identificare le competenze maggiormente influenzate dall'utilizzo della didattica a distanza. I dati mostrano scarse differenze in ordine al tipo di competenze acquisite. Le differenze più significative sono correlate al cambio di docente. In alcune sedi si rilevano differenze nella soddisfazione degli studenti. Gli studenti del cluster 2021 ritengono che la loro valutazione rifletta le loro conoscenze realmente acquisite, a differenza del cluster di studenti del 2020. La metodologia illustrata nel presente contributo fa riferimento ad uno strumento utile per la valutazione della qualità degli apprendimenti basata sul feedback degli studenti. Le limitazioni connesse allo studio riguardano le modalità di rilevazione dei dati. Gli studenti non sono tenuti a partecipare allo studio. L'autovalutazione non è sufficiente per convalidare le competenze acquisite, consente però di rilevare la soddisfazione e la qualità percepita dagli studenti.

Parole chiave: Apprendimento online; impatto COVID; competenze; laurea in informatica. 


\section{Introduction}

The efficiency and cross-border comparison of educational systems play an increasing role in society. Mention should be made here of the PISA study of the OECD concerning the competence achievements of (primary and secondary) school systems (see for example OECD PISA 2021, accessed 1 Dec. 2021 https://www.oecd.org/pisa/).

Essential for such competence measurements and for the comparability of the results are models that define measurable variables in connection with the (diverse) competence goals to be achieved. In such models, a distinction is usually at least made between subjectspecific and methodological competence goals, or even such models are developed subjectspecifically (see for example Clear et al., 2020; Magenheim et al., 2013; Pasternak or Hellmig, \& Röhner, 2018 in the field of Computer Science). Similar approaches for higher education are still less popular or fail due to the lack of participation of the many different actors, or a conventional (sometimes contradicting) understanding of freedom of teaching, or a lack of uniform educational plans and competence goals. As a result, competence measurements in higher education are understudied with few examples, such as Bröker, Kastens, \& Magenheim, 2015; Clear, Parrish, Impagliazzo, \& Zhang, 2019; Frezza et al., 2018; Leutner et al., 2017a; 2017b. On the other hand, with the Bologna Agreement and the associated Bologna Process, a basis was created that enables the respective educational plans and study programs to be compared (see for example Consolidating Higher Education Experience of Reform 2018, accessed 1 Dec. 2021 http://www.processodibologna.it).

In the various stages of development of accreditation according to the European Credit Transfer System (ECTS), the model of comparable lecture structures and the comparable competence goals formulated therein has become more and more popular, which is also the prerequisite for the mutual recognition of lecture achievements and degrees at the European level. When formulating the various competency goals, it should be taken into account that the various competency dimensions are reflected on and formulated explicitly within each lecture. Among the various competence models that can be used to explore these dimensions we mention the AKT model (Anderson \& Krathwohl, 2001) which is cited in the recommendations for the "Bachelor in Computer Science" Curriculum by the German Computer Science Society (Liggesmeyer, 2018). On the other hand, the Dublin descriptors are often used to designate these competence dimensions. In the following, we refer to the Dublin descriptors due to their relevance in the European context of education (see for example Gudeva, Dimova, Daskalovska, \& Trajkova, 2012; Hoffmann et al., 2009; Lile \& Bran, 2014; Riabchykov \& Khurana, 2019).

The COVID pandemic, starting in 2020, has forced all students online, often attending lectures from their bedroom. At the time of this study, two groups or cohorts of students have graduated with COVID semesters. The group in 2020 took their last semester online, while the 2021 graduating group participated in three semesters online, which presents half of their Bachelor degree. Rumour has it among the teaching staff, that this is a very challenging, coerced situation for students and not all are able to cope with its novelty, which we wanted to quantify. Even though, several studies have been completed to analyse the pandemic situation in higher education (see for example Berkling, 2020; Berkling, Saller, \& Winter 2021; Crick, Knight, Watermeyer, \& Goodall, 2020; Federighi, 2018; Möbs, Berkling \& Saller, 2021; Souleles, Laghos \& Savva, 2020; Tang et al., 2021; Tomková \& Bánesz, 2020; Torlone, 2018; 2021; Widodo, Wibowo, \& Wagiran, 2020), competence measurements as a tool for analysis of higher education is still not popular and complex. 
In this work, we develop and apply a simple approach to core competence measurement to our bachelor program in computer science. In the following, we describe the elements and the procedure, with which the graduates over the past two years of the Bachelor's degree in Computer Science at the Baden-Württemberg Cooperative State University were able to evaluate their perceived achievements of the formulated core competence goals in the form of a self-assessment.

The results were used to gain insights into the (perceived) achievement of the competence goals in times of the pandemic. The current study asked students about their self-assessed performance across a representative selection of competences that were sampled across lectures taught across the entire three Bachelor years. The additional goal is to gain a longterm tracking tool in order to find weak and strong points in our curricula. These would be used for improvements and again measured over time.

The rest of the paper is structured as follows. After stating the research questions, the methodology is explained. Results are reported and discussed in conclusion with some remarks about further work and limitations of this work.

\section{Research Motivation}

This research was prompted by the emergency online teaching situation due to the COVID lockdown that required the university to hold their lectures through online platforms. The goal was to find a long-term quality measurement in order to understand whether the lockdown had an impact on teaching and learning. In the process, we have also created a long-term assessment tool based on student feedback that can be used to improve the curriculum and teachings.

We posed the following research questions:

- RQ1: Are there significant differences in self-assessment of competencies due to online teaching by defining specific subgroups (for example by location, by lectures studied, by year, or other clustering mechanisms)?

- RQ2: Are there significant differences in satisfaction with studies by subgroups?

- RQ3: Can students be grouped into clusters by performance? Can we detect that more students moved to the lower performance cluster according to their selfassessed competencies?

\section{Methodology}

This section describes the questionnaires, participants, and the process of data collection and processing. 


\section{Form@re}

Open Journal per la formazione in rete

\begin{tabular}{|c|c|c|}
\hline \multicolumn{3}{|c|}{ Technical skills and knowledge } \\
\hline Dublin Descriptor 1 & \multicolumn{2}{|c|}{ Dublin Descriptor 2} \\
\hline Knowledge and understanding & \multicolumn{2}{|c|}{ Applying knowledge and understanding } \\
\hline Matter & \multicolumn{2}{|c|}{ Method } \\
\hline \multicolumn{3}{|c|}{ Understanding: application of theory and methodology } \\
\hline \multicolumn{3}{|c|}{ Transversal skills and knowledge } \\
\hline Dublin Descriptor 3 & Dublin Descriptor 4 & Dublin Descriptor 5 \\
\hline Making judgement & Communication skills & Learning skills \\
\hline Individual & Social & Overarching \\
\hline Summarize and evaluate & Ability to communicate & Ability to learn and to develop \\
\hline
\end{tabular}

Figure 1. Dublin Descriptors.

\begin{tabular}{|c|c|c|c|}
\hline GI Subcategories & GI Topics & DHBW Lecture & Year \\
\hline \multirow[t]{3}{*}{$\begin{array}{l}\text { Mathematics for com- } \\
\text { puter scientists }\end{array}$} & $\begin{array}{l}\text { Discrete structures, logic and } \\
\text { algebra }\end{array}$ & Mathematics I, II & 1 \\
\hline & Analysis and numerics & Mathematics I, II & 1 \\
\hline & $\begin{array}{l}\text { Probability theory and Statis- } \\
\text { tics }\end{array}$ & Mathematics I, II & 2 \\
\hline \multirow[t]{3}{*}{$\begin{array}{l}\text { Theoretical computer } \\
\text { science }\end{array}$} & $\begin{array}{l}\text { Formal languages and } \\
\text { automata }\end{array}$ & $\begin{array}{l}\text { Theoretical Computer } \\
\text { Science I-III } \\
\text { Compiler construction }\end{array}$ & 2 \\
\hline & Modeling & $\begin{array}{l}\text { Theoretical Computer } \\
\text { Science I-III }\end{array}$ & 2 \\
\hline & $\begin{array}{l}\text { Algorithms and data } \\
\text { structures }\end{array}$ & $\begin{array}{l}\text { Theoretical Computer } \\
\text { Science I-III }\end{array}$ & 1 \\
\hline \multirow[t]{2}{*}{$\begin{array}{l}\text { Software engineering } \\
\text { and programming }\end{array}$} & $\begin{array}{l}\text { Programming languages and } \\
\text { methodology }\end{array}$ & $\begin{array}{l}\text { Programming Web } \\
\text { engineering }\end{array}$ & 1 \\
\hline & Software engineering & Software engineering $\underline{\underline{1, I I}}$ & 2,3 \\
\hline \multirow[t]{2}{*}{$\begin{array}{l}\text { Human-computer inter- } \\
\text { action }\end{array}$} & Human-computer interaction & $\begin{array}{l}\text { Introduction to robotics } \\
\text { Artificial intelligence }\end{array}$ & 3 \\
\hline & & $\begin{array}{l}\text { Computer graphics and image } \\
\text { Processing } \\
\text { e-Business }\end{array}$ & \\
\hline Key skills and practice & Project and team skills & Key skills $\underline{\underline{I}, I}$ & 1 \\
\hline \multirow[t]{3}{*}{$\begin{array}{l}\text { Elements, architectures } \\
\text { and processes }\end{array}$} & $\begin{array}{l}\text { Digital technology and com- } \\
\text { puter organization }\end{array}$ & Technical informatics I, II & 1,2 \\
\hline & Operating systems & Technical informatics I, II & 2 \\
\hline & $\begin{array}{l}\text { Databases and information } \\
\text { systems }\end{array}$ & Databases I, II & 2 \\
\hline \multirow[t]{3}{*}{ Networks and Security } & $\begin{array}{l}\text { Computer networks and } \\
\text { distributed systems }\end{array}$ & $\begin{array}{l}\text { Communication and network } \\
\text { technology I, II }\end{array}$ & \\
\hline & & $\begin{array}{l}\text { Software quality and } \\
\text { distributed systems }\end{array}$ & 2,3 \\
\hline & IT security & IT security & 3 \\
\hline
\end{tabular}

Figure 2. Categories of "German Informatics Society" (GI) with assigned lectures and year of study. 


\subsection{Instruments}

In order to measure competencies through self-assessment, each competence from all computer science lectures were sorted into a matrix of Computer Science areas given by "Gesellschaft für Informatik" (see Bildungsstandards, 2008)) as shown in Figure 2 and the hierarchical skills of the Dublin Criteria (see for example Gudeva et al., 2012) that are listed in Figure 1. From this matrix, core competences were chosen as representative for the three years, covering a wide spectrum of various competences as categorised in Figure 3. Students are asked to answer a questionnaire that takes between 30-60 minutes. The 38 competency items were written up in German rated on a 10-point Likert scale to provide a large scale that has been proven effective for measuring skills in our setting. Three additional general items were added to the survey and rated on a smaller Likert-scale of 5:

- Do you feel ready for the job market? ${ }^{1}$

- Do your grades agree with your own self-assessment?

- Are you satisfied with your studies?

The questionnaire was administered on our internal survey system evasys (https://evasys.de/en/) to graduates during August to October in both 2020 and 2021. The link to the survey was sent to professors in all subsidiaries who were asked to send the link to their students. The letter included information about the importance of quality assessment through student feedback to judge the effect of COVID and generally gain an instrument for long-term tracking of feedback from graduates.

\begin{tabular}{ll}
\hline Dublin Descriptors & items \\
\hline DD1 (Knowledge and understanding) & 9 \\
DD2 (Applying knowledge and understanding) & 7 \\
DD3 (Making judgement) & 5 \\
DD4 (Communication skills) & 6 \\
DD5 (Learning skills) & 11 \\
total & 38 \\
\hline Gl Topics & 2 \\
\hline Mathematics for computer scientists & 8 \\
Theoretical computer science & 7 \\
Software engineering and programming & 2 \\
Human-computer interaction & 5 \\
Key skills and practice & 10 \\
Elements, architectures and processes & 4 \\
Networks and security & \\
\hline
\end{tabular}

Figure 3. Categorisation of items by GI Topics and Dublin Descriptors.

\subsection{Data Collection and Participants}

The study was conducted at the Cooperative State University of Baden-Württemberg. Small cohorts of around 30 students complete the three years of their Bachelor program, alternating between academia and industry in a quarter-based system. The students hold contracts with industry and are salaried during this time. The University has 12 subsidiaries and over 30.000 students across the state. The 2020 group contained 84 graduates from 6 locations while the 2021 survey was answered by 70 graduates from 5 locations, respectively. The return rate is quite low (10-20\%) because students already graduated and

\footnotetext{
${ }^{1}$ The ability to judge with regard to this item is assumed to be quite high for DHBW students, since their studies take place in a job-integrated manner.
} 
due to the length of the survey. Three reminders were sent out, students were asked directly and cooperative partners sent out an additional email asking their students who are also employees to participate in the study.

\subsection{Data Processing}

Survey data was downloaded from Evasys in form of .xlsx files that were then processed using R. The additional general items on a Likert-scale from 1-5 where normalised into a scale of 1-10 to be comparable with the other item ratings. The number of single items by topic can be seen in Figure 3. In order to answer the research questions, it is possible to analyse the joint items across both years along several dimensions, such as lecture, year of graduation, or Dublin Descriptor (which is outside of the scope of this paper). Moreover, in order to study the effect of online vs on-premise teaching, this data allows us to group the data across student from both years by lectures that were taught online and those that were taught on-premise (this differed by year of graduation).

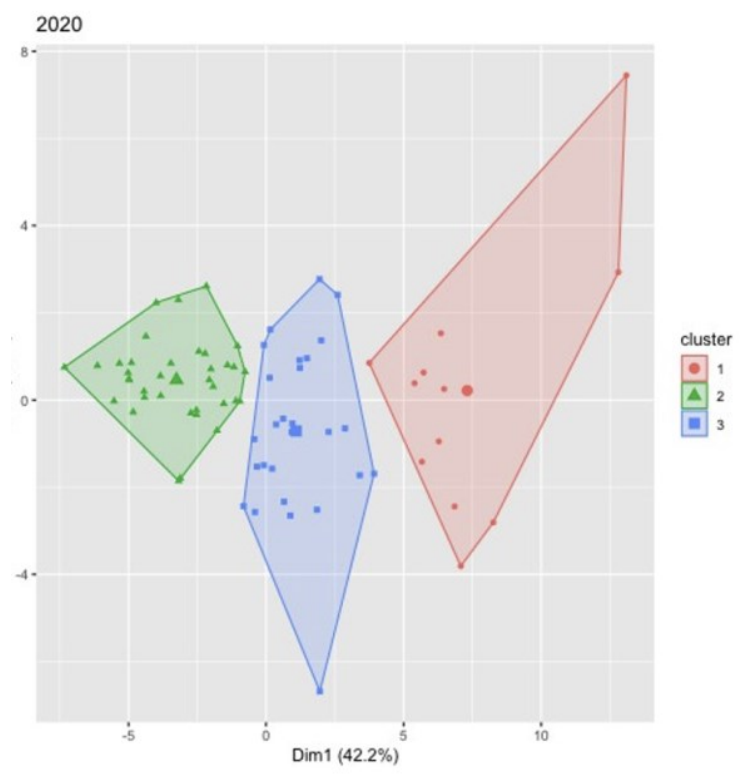

Figure 4. Visualisation of the K-means Clusters along the two first most discriminating axes.

In addition to linear analysis, all data from 2020 was combined in order to cluster students into three groups, taking into account correlations between the items. The number of clusters was chosen to cover the main groups that are known from teaching, ie. those that do very well, those that form the prototypical middle and those students that have a hard time. Two clusters are generally not sufficient to describe the pool. The list of student feature vectors was given to the k-means clustering algorithm in R as shown in Kassambara (2017). The classifier was trained to be able to classify any student upon presentation of the survey response as feature vector. In order to map a new student, the corresponding feature vector is simply presented to the classifier who then sorts it into one of the 3 categories that it was trained to recognise. Figure 4 shows the resulting clustering for the 2020 group. 


\section{Results}

Results are reported, addressing each of the research questions by looking at competency achievements for the cohorts, comparing the general questions, and analysing sub-groups of students.

\subsection{Comparing Assessments between 2020 and 2021}

Next, we looked at the overall self-rating across all lectures and all students from two different perspectives. Firstly, we compared the two groups of by year of graduation, 2020 and 2021. Secondly, we merged both 2020 and 2021 groups and separated them according to modules that were taken online and modules that were taught on-premise.

\begin{tabular}{l|crr|rrr}
\hline & p-value & N online & N on premise & p-value & N 2020 & N 2021 \\
\hline all & .65 & 938 & 4536 & .24 & 3192 & 2660 \\
8T $^{\star *}$ & .01 & 174 & 1134 & .00 & 789 & 456 \\
BI & .94 & 142 & 270 & .69 & 190 & 456 \\
C8 $^{*}$ & .01 & 177 & 918 & .62 & 646 & 494 \\
R8* $^{*}$ & .09 & 278 & 972 & .00 & 684 & 836 \\
W* $^{*}$ & .11 & 114 & 702 & .02 & 494 & 304 \\
\hline
\end{tabular}

Figure 5. Number of modules rated by students belonging to particular subgroup along with $p$ value $(\mathrm{p}<.05$ is significant).

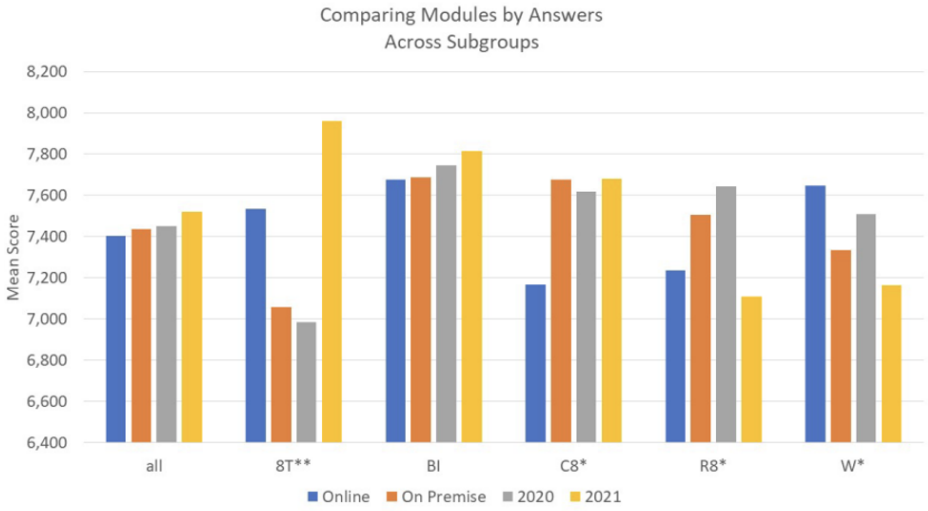

Figure 6. Comparing self-assessment across all modules by subgroups. Firstly, by year of graduation; secondly, by online vs. on premise modules.

Both results are depicted in Figure 6 by plotting the mean values of each of the subgroups given by the respective DHBW locations. For the sake of anonymity, we have encoded the location names by "8T", "R8", "BI" , "C8" and "W". Figure 5 lists the p-values for each comparison and the number of samples for each of the subgroups. Numbers ' $N$ ' differ because not all modules were considered in the online vs. on premise subgroups.

Three locations show significant changes from Group 2020 to Group 2021. "8T" decreased, "R8" increased, and "W" decreased in the self-assessment mean value. In general, one would expect a decrease in Group 2021 because of the three online semesters.

\subsection{Comparing Assessments between Online and On-Premise Modules}


In order to compare self-assessments for online lectures (modules) vs. on-premise modules, all modules are assumed to be taught with regard to the timetable of the standard curriculum. Hence, as online modules were counted all modules of Year 3 from Group 2020 and Years 2 and 3 from Group 2021. As modules taught on-premise, we counted Years 1 and 2 from Group 2020 and Year 1 from Group 2021. Looking at the group jointly across all locations, no significant differences were found between either of the two compared subgroups.

However, when drilling down to the subsidiaries we can see some significant differences between subgroups and also between subsidiaries. " $8 \mathrm{~T}$ " displays not significant difference for any of the subgroups regarding the self-evaluation of the skills achieved across the relevant modules. " $8 \mathrm{~T}$ " shows two significant differences. Modules that were taught onpremise were evaluated significantly lower than those that were taught online. At the same time, Group 2021 has a higher self-evaluation than Group 2020 even though they had more online time than Group 2020. "BI" shows no significant difference between any groups. "C8" has significant higher self-evaluation on modules that are taught on-premise than online. Group 2021 has an only slightly higher evaluation of the modules than Group 2020. "R8" has a higher score for on-premise modules than online modules but scores significantly lower for modules in Group 2021 than Group 2020. "W" has lower on-premise evaluation than online evaluation. However, significant is the lower median score of selfassessment for Group 2021 compared to Group 2020.

" $8 \mathrm{~T}$ " and "C 8 " have significant changes in self-evaluations between online and on-premise modules. "C8" has higher performance on-premise, " $8 \mathrm{~T}$ " has lower performance onpremise. The differences between the locations demonstrate why no change is observed for all responses taken together. Location seems to play a significant role in success and the subsidiaries should look into the data with more detail and one could learn from each other.

In summary, there are significant differences between online and on-premise modules concerning the self-evaluation of corresponding skills. There are also significant differences between the years. There is no general trend. So, one hypothesis could be that there are specific teachers or platform set-ups in particular locations that make online learning better, while other locations struggle with going online. The data also show that the general differences between the two years are not the same as those between online and on-premise, even though Group 2021 had one year more online modules than Group 2020.

\subsection{Comparing Meta-Data between 2020 and 2021}

Looking at the overall distribution across all students for the general three questions given in Section 3.1, no major differences can be seen across the 2020 and 2021 groups. Figure 7 shows the different density functions by location. The title gives the mean of the distribution as well as the p-value if it is significant (Row depict locations in order BI, C8, R8, 8T, and W. Columns depict "Readiness for Work", "Agreement between grades and self-assessment", and "Satisfaction with Studies").

- Do you feel ready for the job market? No clear changes since last year have been noted regarding preparation for the job market. "BI" has the highest score. "R8" seems to have suffered the most in the peak area of score 10 in 2021. In general, there is room for improvement in these scores.

- Do your grades agree with your own self-assessment? All locations have a change in the degree to which students believe that their grades agree with their selfassessment. While it is still rather high, the agreement has decreased. " $8 \mathrm{~T}$ " has the 
highest change though it is not significant with $p$-value of $.07>.05$, however the bump on the lower side of the distributions is disconcerting. "C8" has a slightly better agreement between grades and students' impression of their own skills.

- Are you satisfied with your studies? It can be seen in the graphics, that the general tendency is less satisfaction in their studies for the group 2021 when compared to group 2020. While satisfaction is rather high in general for both years and all locations, some locations do have a higher degree of satisfaction among students. " $8 \mathrm{~T}$ " has the least change. "R8" and "C8" have the highest change but neither is significant with p-value above $.05 \mathrm{p}$-value.

\subsection{Comparing Assessments by Year (1, 2, 3, 1-2, 2-3)}

For each competence, the self-assessments of both groups 2020 and 2021 were compared using the t-test in order to determine the p-value. A p-value below .05 reflects a significant difference between two distributions. Looking at all groups jointly by year of study, no differences were evident. When comparing each competence separately for each location, one can only find specific differences that would allow us to determine differences only for single competences.
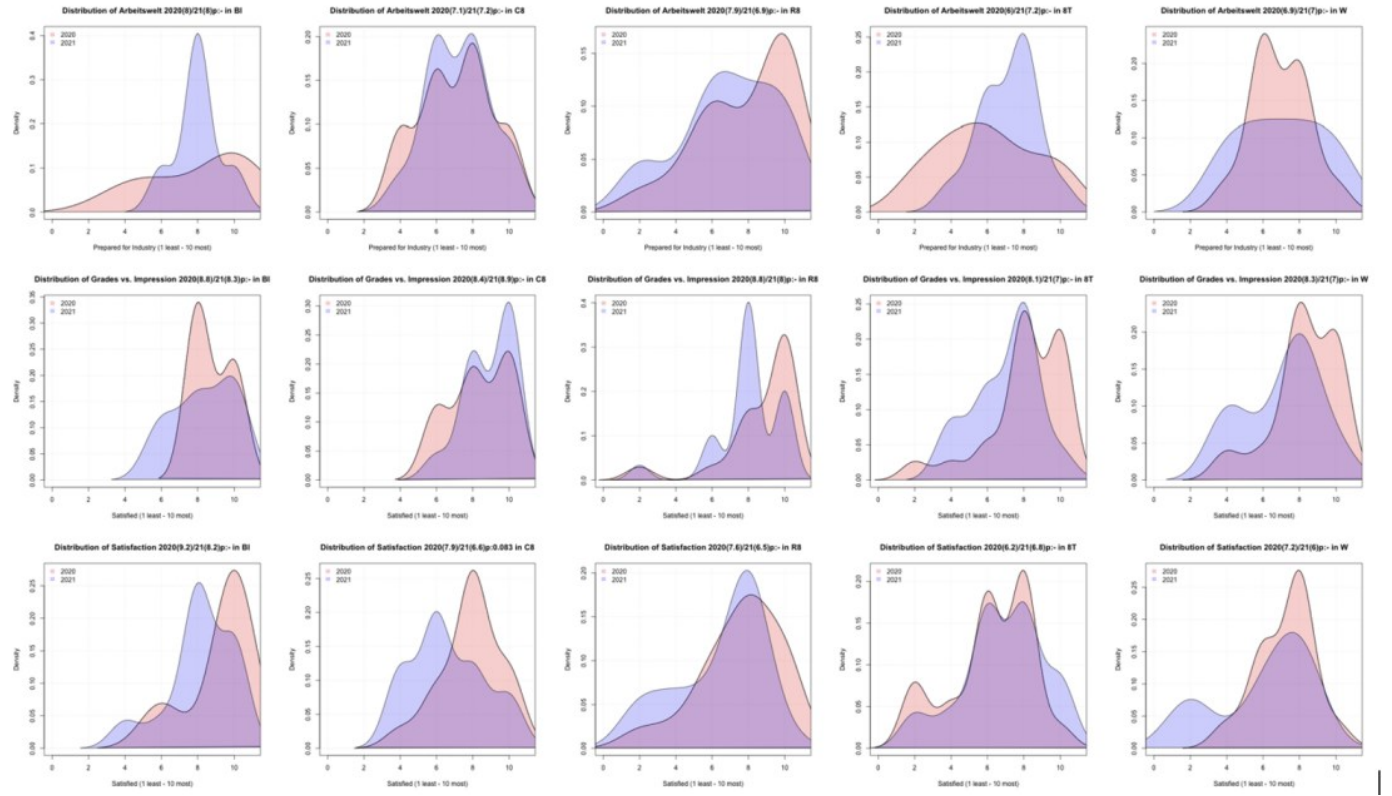

Figure 7. Comparing densities of general questions about readiness for work, grades agreeing with self-assessment and overall satisfaction with studies rated from 1-5 but shown here normalised from 1(low)-10(high).

We conclude that the differences are not due to COVID but seem to relate more specifically to lectures, lecturers or course compositions. Thus, they are not part of this study. No COVID effects can be discovered using this methodology.

\subsection{Analysing Subgroups of Students}

Both 2020 Group and 2021 Group of students are classified into the three clusters using the classifier described in Section 3.3. Figure 8 displays the distribution of self-rating answers for all items for each of the subgroups. Across all locations, it can be seen that the $\%$ of 
students falling into each of the three categories is similar for both years. The distributions within each of the classes furthermore show that they can be roughly names "Low", "High", and "Middle" self-assessment for Cluster 1-3 respectively. Using the classifier trained on Group 2020 shows similar split into these three clusters when looking at the distributions.

Cluster $1 \cdot 21 \mathrm{n}=15 \%$

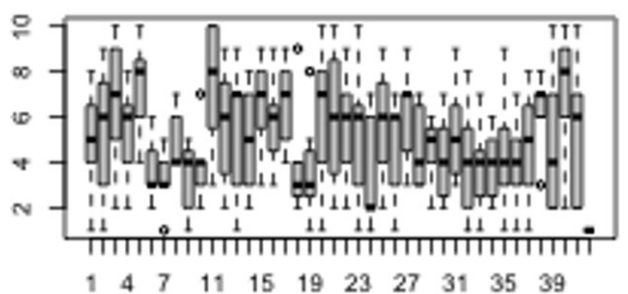

Cluster $2 \cdot 21 \mathrm{n}=46 \%$

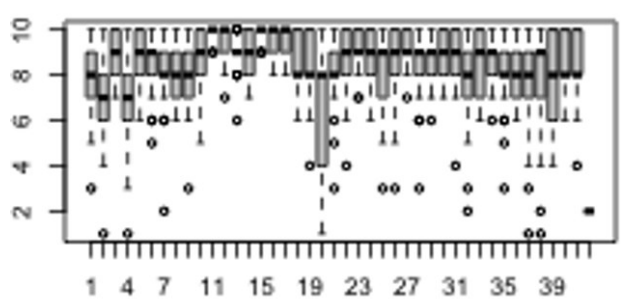

Cluster $3-21 n=39 \%$

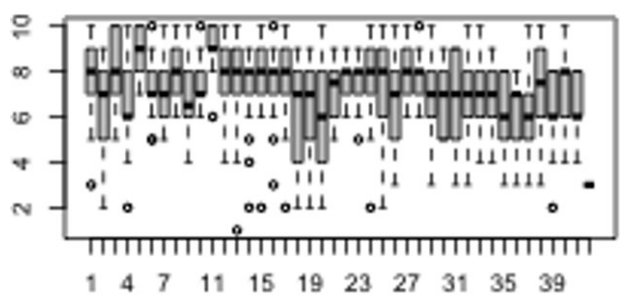

Cluster $1 \cdot 20 \mathrm{n}=16 \%$

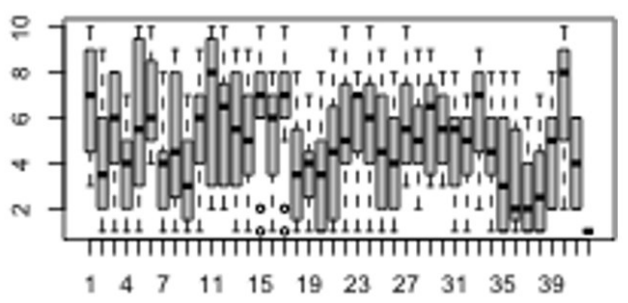

Cluster $2 \cdot 20 \mathrm{n}=48 \%$

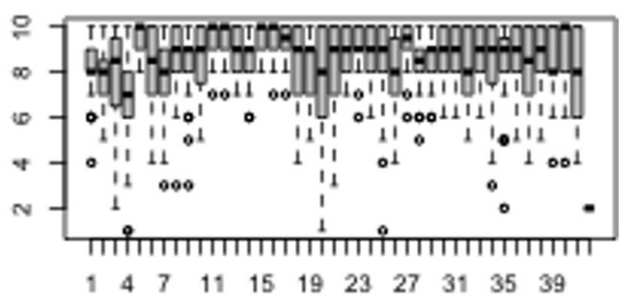

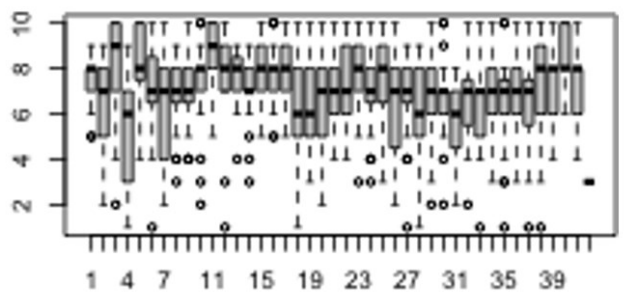

Figure 8. Distributions of self-ratings across items by cluster for Group 2020 and Group 2021. The $\%$ of students falling into each group is given. Cluster $1=$ "Low", Cluster $2=$ "High", and Cluster $3=$ "Middle".

While the overall group sizes did not change significantly across both years, as shown in Figure 9 without normalisation, there are differences between the locations. For example, "R8" has gained a larger number of students in the "Low" cluster and reduced the number of students in "High" cluster. "C8" and "BI" however, both shrank their "Low" group and grew the "Middle" group. It is important to note two ideas here: Firstly, this diagram does not reflect the number of drop-out students that did not enter into the statistics anymore. Secondly, the self-assessment of a student in one location may not equate to the selfassessment in another location as it could be a culturally biased and may or may not reflect the actual skill level. 


\section{Form@re}

Open Journal per la formazione in rete
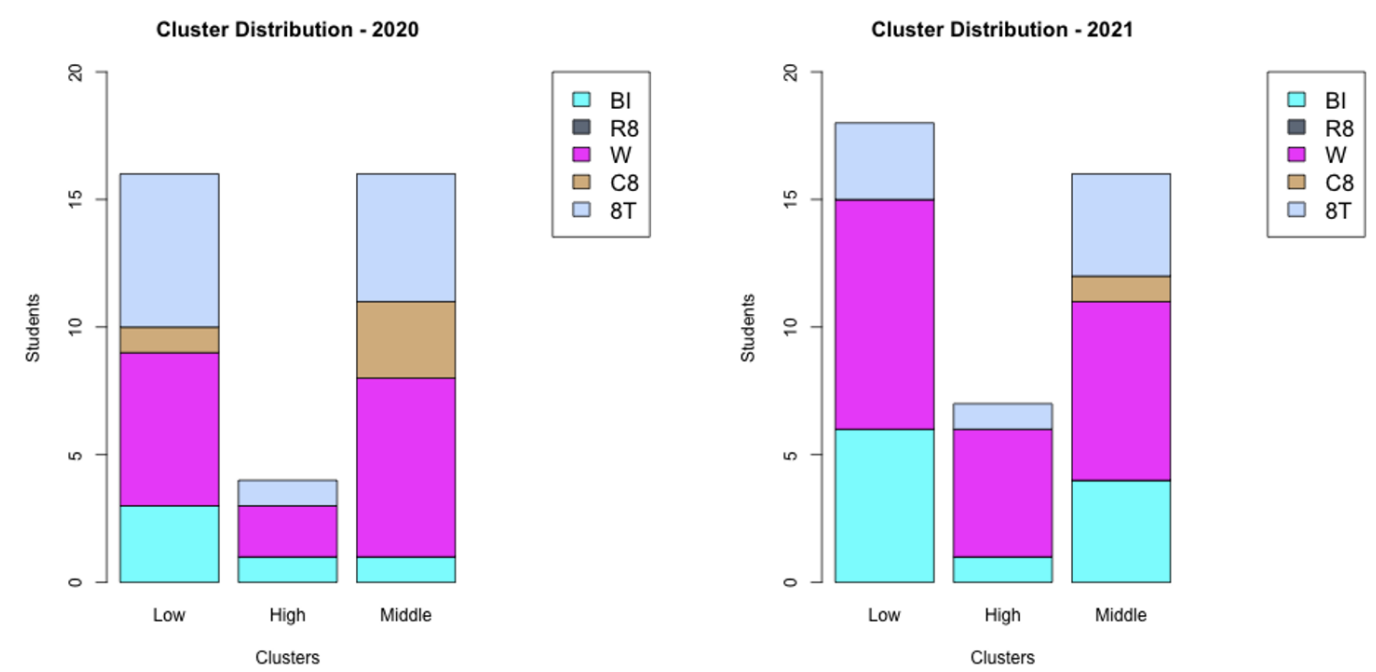

Figure 9. The plots compare the amount of students in each of the three clusters for 2020 and 2021 graduates. Only those locations appearing in both studies are plotted.

\section{Discussion and Conclusion}

The goal of this study was to understand whether COVID had an impact on our students from the point of view of achieving competencies. The fear was, that online teaching would not allow students to learn the material to the same degree. Anecdotal evidence suggested that we had lost students that otherwise would have succeeded. Using the self-assessment method, we hoped to obtain feedback on students' impressions of their own competencies.

- RQ1: Are there significant differences between the two groups in self-assessment of competencies that can be attributed to online teaching? Regarding the competency self-assessment, no clear tendency can be seen that affects the group as a whole or all competencies taught online. Some locations have specific clusters of competences in any of the years that improved or declined from one cohort to the next. These do not seem to be correlated to online or on site teaching and should be addressed separately from this study. However, comparing sub-groups, some findings can be attributed to COVID, see RQ3 below.

- RQ2: Are students satisfied with their studies in the same way for both groups? The general questions that did not relate to specific skills but impressions about grade, satisfaction and job readiness do show changes from 2020 to 2021 that all seem to be related to COVID because the tendency is general enough across groups and locations. There was a decline for all ratings. Even though the changes were not significant and the scores are generally still high, it is worth addressing these issues in more detail.

- RQ3: Can students be grouped into clusters by performance? Can we detect that more students moved to the lower performance cluster according to their selfassessed competencies? In the work presented, we claim that it is possible to cluster students into three subgroups that generalise across the years by allowing us to split the groups into three performance subgroups according to their own assessments. If this is true, then it is also possible to see whether one or the other of the clusters shrinks or grows. If the group of students that give themselves low self-assessment 
grows, then this seems problematic. The data seems to indicate that in this was the case from 2020 to 2021 for some locations. Two limitations to these findings are the low number of responses, the fact that some students already dropped out by the time the survey was given and that self-assessment may have a locationdependent cultural bias. The changes are significant enough to warrant a deeper look.

Based on these findings, we feel that the current survey has proven effective to capture changes over time. Several areas of weakness and strengths have been identified by competence and by location. While this questionnaire is administered after graduation, it would be interesting to conduct the survey after completion of each year, separating the years cleanly, surveying closer to the time the skill was taught, and capturing problems earlier, reducing the time taken for the survey and perhaps thus increasing the number of students who participate. Because the information obtained from these surveys is very important, it should be made obligatory for students.

Limitations of this study relate to the low number of participants by location. Location plays a major role in students' responses. More years are needed to determine clear trends and attributing these to online studies.

\section{Acknowledgement}

We would like to thank students who took the time to partake in this survey to help us understand how to improve the online experience. Also, a big thanks to the participating subsidiaries and the support from those who sent out invitations to the survey and encouraged students to participate. This work is part of the international CLUE project, which is happy to find new partners (https://www.researchgate.net/project/CLUE-CoronaLockdown-University-Experience).

\section{References}

Anderson, L. W., \& Krathwohl, D. R. (2001). A taxonomy for learning, teaching, and assessing: A revision of Bloom's taxonomy of educational objectives. Longman.

Berkling, K. (2020). Contrasting the user experience between educator and student during corona semester at university. In L. Gómez Chova, A. López Martínez, \& I. Candel Torres (Eds.), ICERI Proceedings, ICERI2020 Proceedings (pp. 4002-4011). doi.org/10.21125/iceri.2020.0901 (ver. 15.12.2021).

Berkling, K., Saller, D., \& Winter, C. (2021). Online learning readiness - determining key factors that distinguish university students who feel comfortable with online studies. In L. Gómez Chova, A. López Martínez, \& I. Candel Torres (Eds.), ICERI Proceedings, ICERI2021 Proceedings (pp. 6962-6970). doi.org/10.21125/iceri.2021.1575 (ver. 15.12.2021).

Bildungsstandards, A. (2008). Grundsätze und Standards für die Informatik in der SchuleBildungsstandards Informatik in der Sekundarstufe I', Beilage zu: LOGIN, 150, $151,1-72$. 
Bröker, K., Kastens, U., \& Magenheim, J. (2015), Competences of Undergraduate Computer Science Students, KEYCIT 2014 key competencies informatics ICT, 7, 77-96.

Clear, A., Clear, T., Vichare, A., Charles, T., Frezza, S., Gutica, M., Lunt, B., Maiorana, F., Pears, A., Pitt, F., Riedesel, C., \& Szynkiewicz, J. (2020). Designing Computer Science Competency Statements. In Rößling, G., Krogstie, B. R., Giannakos, M., Sindre, G., Luxton-Reilly, A. \& Divitini, M. (Eds.), Proceedings of the Working Group Reports on Innovation and Technology in Computer Science Education, 211-246.

Clear, A., Parrish, A. S., Impagliazzo, J., \& Zhang, M. (2019). Computing Curricula 2020. In E. K. Hawthorne, M. A. Pérez- Quiñones, S. Heckman, \& J. Zhang (Eds.), Proceedings of the 50th ACM Technical Symposium on Computer Science Education, 653-654.

Crick, T., Knight, C., Watermeyer, R., \& Goodall, J. (2020). The Impact of COVID-19 and "Emergency Remote Teaching" on the UK Computer Science Education Community. In J. Maguire \& Q. Cutts (Eds.), United Kingdom \& Ireland Computing Education Research conference, 31-37.

Federighi, P (2018). The core contents of pedagogy for the first degree in Education Sciences.Form@re - Open Journal per la Formazione in Rete, 18(3), 19-36.

Frezza, S., Daniels, M., Pears, A., Cajander, Å., Kann, V., Kapoor, A., McDermott, R., Peters, A. K., Sabin, M., \& Wallace, C. (2018). Modelling competencies for computing education beyond 2020: a research based approach to defining competencies in the computing disciplines. In G. Rößling \& B. Scharlau (Eds.), Proceedings Companion of the 23rd Annual ACM Conference on Innovation and Technology in Computer Science Education, 148-174.

Gudeva, L. K., Dimova, V., Daskalovska, N., \& Trajkova, F. (2012). Designing descriptors of learning outcomes for Higher Education qualification. Procedia-Social and Behavioral Sciences, 46, 1306-1311.

Hoffmann, M. H., Grunberg, J., Hampe, M., Heiss, H. U., Muller, G., \& Schmitt, H. (2009). A sectoral qualifications framework for engineers and computer scientists. In 2009 EAEEIE Annual Conference, IEEE, 1-5.

Hoffmann, M. H., Hampe, M., Müller, G., Bargstädt, H. J., Heiß, H. U., \& Schmitt, H. (2010). Knowledge, skills, and competences: Descriptors for engineering education. In IEEE EDUCON 2010 Conference (pp. 639-645). IEEE.

Kassambara, A. (2017). Practical guide to cluster analysis in R: Unsupervised machine learning (Vol. 1). Sthda.

Leutner, D., Fleischer, J., Grünkorn, J., \& Klieme, E. (Eds.). (2017a). Competence Assessment in Education, Methodology of Educational Measurement and Assessment. Springer.

Leutner, D., Fleischer, J., Grünkorn, J., \& Klieme, E. (2017b). Competence assessment in education: An introduction. In D. Leutner, J. Fleischer, J. Grünkorn \& E. Klieme, (Eds.), Competence assessment in education (pp. 1-6). Springer.

Liggesmeyer, P. (2018), Empfehlungen für Bachelor - und Masterprogramme im Studienfach Informatik an Hochschulen. 
Lile, R., \& Bran, C. (2014). The assessment of learning outcomes. Procedia-Social and Behavioral Sciences, 163, 125-131.

Magenheim, J., Neugebauer, J., Stechert, P., Ohrndorf, L., Linck, B., Schubert, S., Nelles, W., \& Schaper, N (2013). Competence Measurement and Informatics Standards in Secondary Education. In I. Diethelm \& R. T. Mittermeir (Eds.), Informatics in Schools. Sustainable Informatics Education for Pupils of all Ages (pp. 159-170), Berlin, Heidelberg: Springer.

Möbs, S., Berkling, K., Saller, D. (2021). Teaching and Learning in times of Corona. Didattica a Distanza: esperienze dal lockdown, Quaderni del Dipartimento di Linguistica - Università della Calabria, 28(2020), 103-117.

Pasternak, A., Hellmig, L., \& Röhner, G. (2018). Standards for Higher Secondary Education for Computer Science in Germany. In International Conference on Informatics in Schools: Situation, Evolution, and Perspectives (pp. 117-128). Cham: Springer.

Riabchykov, M. \& Khurana, K. (2019), Universal Matrix Model f Formation fCompetence with Account of the Functions of Activity and Measurement of Learning Results Based on Dublin Descriptors. In Problems of Engineering and Pedagogy (Проблеми інженерно-педагогічної освіти), (64), pp. 48-61, DOI: 10.32820/2074-8922-2019-64-48-61.

Souleles, N., Laghos, A., \& Savva, S. (2020). From face-to-face to online: assessing the effectiveness of the rapid transition of higher education due to the coronavirus outbreak. In Proceedings of ICERI2020 Conference (Vol. 9, p. 10th).

Tang, Y. M., Chen, P. C., Law, K. M., Wu, C. H., Lau, Y. Y., Guan, J., ... \& Ho, G. T. (2021). Comparative analysis of Student's live online learning readiness during the coronavirus (COVID-19) pandemic in the higher education sector. Computers \& Education, 168, 104211.

Tomková, V., \& Bánesz, G. (2020). Effectivity of distance education of university students during covid-19 pandemic. In ICERI2020 Proceedings, IATED, 13th annual International Conference of Education, Research and Innovation.

Torlone, F. (2018). Methods, tools and instruments for the core contents' definition of the First degree in Education Sciences. Form@re-Open Journal per la formazione in rete, 18(3), 37-60.

Torlone, F. (2021). Contenuti core di un Corso di studi e gestione dei colloqui individuali di orientamento. Educational Reflective Practices-Open Access, 2(2021), 114136.

Widodo, S. F. A., Wibowo, Y. E., \& Wagiran, W. (2020). Online learning readiness during the Covid-19 pandemic. Journal of Physics: Conference Series, 1700, 012033. 